\title{
Thermal treatment for radioactive waste minimisation
}

\author{
Matti Nieminen ${ }^{1, *}$, Markus Olin ${ }^{1}$, Jaana Laatikainen-Luntama ${ }^{1}$, Stephen M. Wickham ${ }^{2}$, Slimane Doudou ${ }^{2}$, \\ Adam J. Fuller ${ }^{2}$, Jenny Kent ${ }^{2}$, Maxime Fournier ${ }^{3}$, Sean Clarke ${ }^{4}$, Charlie Scales ${ }^{4}$, Neil C. Hyatt ${ }^{5}$, \\ Sam A. Walling ${ }^{5}$, Laura J. Gardner ${ }^{5}$, Stephane Catherin ${ }^{6}$, and Benjamin Frasca ${ }^{6}$ \\ ${ }^{1}$ VTT Technical Research Centre of Finland Ltd, Tietotie 4C, 02044 VTT, Espoo, Finland \\ ${ }^{2}$ Galson Sciences Ltd, 5, Grosvenor House, Melton Road, Oakham, Rutland LE15 6AX, UK \\ 3 CEA, DEN, DE2D, SEVT, 30207 Bagnols-sur-Cèze, France \\ ${ }^{4}$ National Nuclear Laboratory, Sellafield, Seascale CA20 1PG, UK \\ ${ }^{5}$ Department of Materials Science \& Engineering, The University of Sheffield, Mappin Street, Sheffield S1 3JD, UK \\ ${ }^{6}$ Waste Packages and Material Department, R\&D Division, Andra, 1-7 rue Jean Monnet, 92298 Châtenay-Malabry cedex, \\ France
}

Received: 12 March 2019 / Accepted: 18 September 2019

\begin{abstract}
Safe management of radioactive waste is challenging to waste producers and waste management organisations. Deployment of thermal treatment technologies can provide significant improvements: volume reduction, waste passivation, organics destruction, safety demonstration facilitation, etc. The EC-funded THERAMIN project enables an EU-wide strategic review and assessment of the value of thermal treatment technologies applicable to Low and Intermediate Level waste streams (ion exchange media, soft operational waste, sludges, organic waste, and liquids). THERAMIN compiles an EU-wide database of wastes, which could be treated by thermal technologies and documents available thermal technologies. Applicability and benefits of technologies to the identified waste streams will be evaluated through full-scale demonstration tests by project partners. Safety case implications will also be assessed through the study of the disposability of thermally treated waste products. This paper will communicate the strategic aims of the ongoing project and highlight some key findings and results achieved to date.
\end{abstract}

\section{Introduction}

The waste hierarchy sets out guidelines for waste managing in order to minimise environmental impact. Priority is on waste prevention and the lowest priority is on disposal. Disposal should be applied when no other alternatives are available and, in this case, the amount of waste to be disposed should be minimised. The principles of the waste hierarchy should also be applied for radioactive waste, though with due regard to safety standards and regulation. Especially in the case of Low and Intermediate Level Waste (LILW), materials are typically contaminated by a very small amount of radioactive isotopes, while the majority of the waste material is not radioactive. For example, in the case of typical operational Low Level Waste (LLW) the actual volume of radioactive isotopes is very low but the total volume of waste is usually large; this is also true for many LILW fractions. The guidelines of the waste

\footnotetext{
* e-mail: matti.nieminen@vtt.fi
}

hierarchy could be followed to minimise the waste volume to be disposed of by thermal treatment of these LILW fractions.

Numerous technologies for thermal treatment of radioactive waste are available or in development worldwide, and more especially in the European Union. These technologies may be applied to a wide range of different radioactive waste streams, including non-standard waste types that present specific waste management challenges. Thermal treatment can result in significant volume and hazard reduction, both of which are beneficial for safe storage and disposal. Thermal treatment also removes organic material, which can form complexing agents and make radionuclides more mobile in a repository.

The European Commission funded THERAMIN project was established to improve awareness and understanding of capability of thermal treatment technologies to treat radioactive waste prior to disposal. The overall objective of the project is to provide improved long-term safe storage and disposal of such LILW streams, which are suitable for thermal treatment. The project enables a coordinated EU-wide research and technology 
demonstration, which are targeted to improve understanding and optimisation of the implementation and use of thermal treatment in radioactive waste management. It is also expected that the project will improve the Technology Readiness Level (TRL) of thermal treatment technologies. The project also enables establishment of a European-wide community of experts on thermal treatment technologies and radioactive waste management and disposal in order to identify efficiencies in national waste management and decommissioning programmes across Europe

\section{THERAMIN project}

The THERAMIN project will make an EU-wide strategic review of the thermal treatment technologies and assessment of the value of technologies applicable for the thermal treatment of a wide range of waste streams like ion exchange resins, soft operational wastes, sludge, organics and liquids. The project also compiles an EU-wide database of such wastes, which would benefit from thermal treatment, and identifies the opportunities, synergies, challenges, timescales and cost implications to improve radioactive waste management. The key activity of the project is an evaluation of the applicability of the technologies and achievable volume reduction of waste through an active and non-active full-scale demonstration trials. Finally, the treated wastes will be characterised and disposability of the product materials and residues will be assessed.

A significant benefit for the project is that the project partners have made large financial and resource investments in thermal treatment $\mathrm{R} \& \mathrm{D}$ facilities already before the THERAMIN project. The project also benefits from close engagement with an End User Group (EUG) representing waste producers and waste management organisations.

The THERAMIN project comprises the following core strands of research: (1) strategic review of radioactive waste streams, (2) demonstration of selected thermal treatment technologies in order to evaluate feasibility of treatment routes for specified waste stream/technology combinations and (3) assessment of disposability of treated wastes by characterising the products and residues from demonstration trials against various Waste Acceptance Criteria (WAC), which are not harmonised in EU. In addition to these technical topics the project is also actively disseminating the results including a training program in order to enhance knowledge of thermal treatment technologies and their benefits.

The project was started in June 2017 and has just passed the halfway point thus a substantial fraction of experimental demonstration program has not yet been completed and thus the final results of the project are not yet available.

\subsection{Strategic review of radioactive waste streams and potential thermal technologies}

One of the first activities of the project was to identify wastes that could potentially be treated using thermal techniques, or where thermal techniques could offer strategic benefits. As a result of this evaluation the following waste categories were identified:

- ion exchange resins, both organic and inorganic, where there is significant volume and organics reduction potential; - soft operational waste including plutonium contaminated material $(\mathrm{PCM})$, where there is also significant volume reduction potential;

- wet wastes such as sludges and liquid wastes;

- wastes with a significant organic content (could include bituminised waste in some countries such as Belgium or Lithuania) with the potential to be chemically reactive and/or give rise to significant gas generation, and which may contribute uncertainty to the post-closure safety case for geological disposal;

- certain types of metallic wastes (e.g. reactor internals, cladding) that are known to cause significant gas generation by corrosion and may contribute uncertainty to the post-closure safety case for geological disposal;

- some types of packaged waste that may have become unacceptable for geological disposal owing to package degradation.

In addition to suitability for thermal treatment, the volume of waste has an essential impact on the assessment of the potential and importance of thermal treatment techniques. The review and assessment of waste volumes turned out more challenging than was expected. Data on low and intermediate radioactive wastes is not easily available in all EU countries and thus the results from the survey are not fully comprehensive. Nevertheless, the survey demonstrated that the need and market potential for thermal treatment technologies is already significant in those countries from which the data were available.

Once the wastes of interest had been identified, an assessment on the thermal facilities available across Europe that could potentially treat these wastes was done. Following a thorough survey, the identified European thermal technologies were grouped into three high level processes: thermal treatment for volume reduction and passivation, conditioning by immobilisation in glass, and conditioning by immobilisation in ceramic or glass-ceramic matrices. For each facility, information on its technical capabilities and availability to treat waste streams were summarised.

- Treatment for volume reduction and passivation included incineration (with burner and refractory walls), rotary kiln incineration, pyrolysis, gasification, calcination, underwater plasma incineration, hydrothermal oxidation and induction metal melter.

- Conditioning by immobilisation in glass included JouleHeated In-Can Vitrification, Joule-Heated Ceramic Melter (JHCM), Cold crucible induction melter (CCIM), Advanced CCIM (A-CCIM), Indirect induction melter (metallic wall - hot metal pot), coupled cold wall direct metal induction melting and plasma burner, coupled cold wall direct glass induction melting and plasma burner and refractory wall plasma burning and melting.

- Conditioning by immobilisation in ceramic, glass or glass-ceramic included Hot Isostatic Pressing (HIP).

Once the technologies and facilities were identified, and the technical details of the thermal processes were assessed, this information was utilised to establish the advantages and limitations of each of the treatment facilities. From 
Table 1. Demonstration technologies and waste materials of the THERAMIN project.

\begin{tabular}{|c|c|c|c|c|}
\hline Technology & Demonstrator & Waste stream & Waste category & Product \\
\hline Shiva & CEA/Orano, France & Organic ion exchange resin & Unconditioned wastes & Vit \\
\hline In Can & CEA/Orano, France & Ashes & Unconditioned wastes & Vitrified \\
\hline GeoMelt 1 & NNL,United Kingdom & Cementito & Conditioned wastes & Vitrified \\
\hline GeoMelt 2 & NNL, United Kingdom & Heterogeneous s & Unconditioned wastes & Vit \\
\hline Thermal gasification & VTT, Finland & Organic ion exchange resin & Unconditioned wastes & Solid residue \\
\hline Vitrification & Vuje/Javys, Slovakia & Chrompik & Liquid wastes & Vitrified \\
\hline HIP & USFD, United Kingdom & Uranium containing sludges & Unconditioned wastes & Vitrified/Ceramics \\
\hline
\end{tabular}

this it was possible to map the identified waste groups to the most suitable or promising technologies. During this mapping exercise each technology was assessed as either being a viable method for treating the given waste, having some potential (either untested, or only with modification) or not being applicable. From this exercise it was clear that there are a wide range of facilities spread across Europe that could potentially treat the identified wastes.

\subsection{Viability of treatment routes for selected waste stream/technology combinations}

The most essential and largest activity of the THERAMIN project is the assessment of the viability of different thermal treatment routes for selected waste stream/technology combinations. This activity is based on experimental demonstrations with six different technologies. The waste materials to be used in the demonstration trials were selected based on the results from strategic review of radioactive waste streams (presented above) and assessment of suitability of the technologies for certain wastes. In addition, one selection criterion was to cover several different waste streams, which are suitable for thermal treatment. The selected waste streams and demonstration technologies are presented in Table 1.

Until now the first test trials have been completed. All thermal treatment facilities to be used in the project have been installed already before the THERAMIN project and financed by other sources but made accessible for the project. The first demonstrations in the autumn 2018 were carried out using following technologies:

- The SHIVA process: cold wall direct glass induction melting and plasma burner (CEA/Orano).

- In-Can Melting process: metallic crucible melter heated in a simple refractory furnace using electrical resistors (CEA/Orano).

- GeoMelt: In Container Vitrification (NNL).

- Thermal treatment process based on thermal gasification (VTT).

- HIP: Hot Isostatic Pressing (NNL and USFD).

\section{The SHIVA process (CEA/Orano)}

SHIVA is an incineration-vitrification process (Fig. 1) well suited for the treatment of organic and mineral waste with

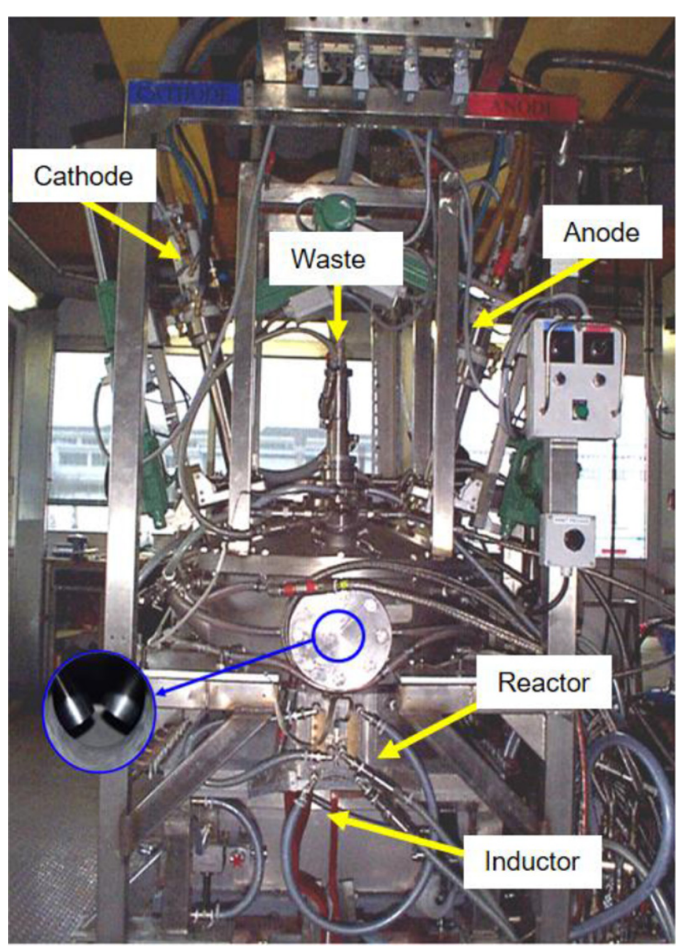

Fig. 1. SHIVA process.

high alpha contamination and potentially high chloride or sulphur content. This technology is specifically designed to operate in a hot cell for high or intermediate level waste. It allows, in a single reactor, waste incineration by plasma burner and ashes vitrification. SHIVA consists of a watercooled, stainless steel cylindrical reactor, equipped with a flat inductor at the bottom and a transferred arc plasma system in the reactor chamber (Fig. 2). The gas treatment consists of an electrostatic tubular filter and a gas scrubber. The waste can be in solid or liquid form but must not contain metals. The SHIVA process has a technology readiness level (TRL) of 5-6 as a full-scale inactive pilot which has been tested by the CEA since 1998 for various wastes. TRL 5-6 means a technology validated/demonstrated in relevant environment (industrially relevant environment in the case of key enabling technologies).

The waste selected for the THERAMIN trial is a $25 \mathrm{~kg}$ mixture of inorganic and organic ion exchange media composed of zeolites, diatoms, strong acid IXR (ion 


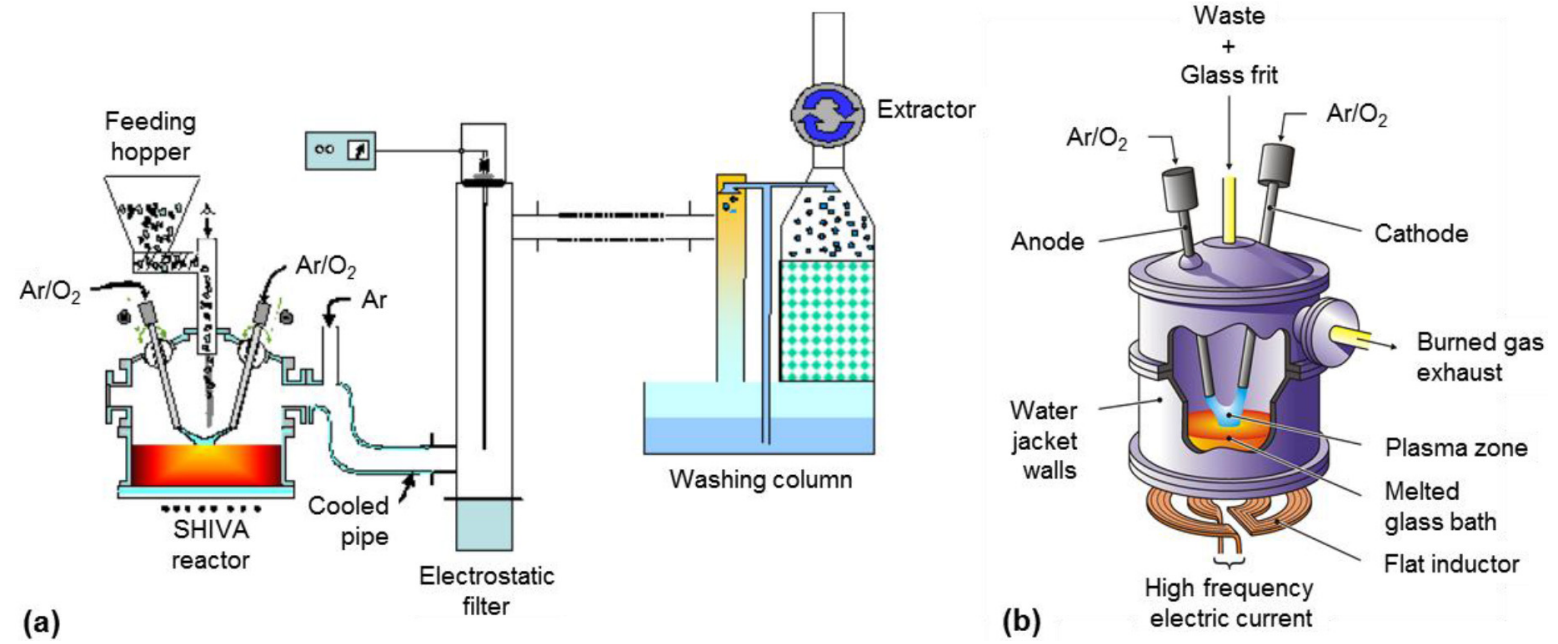

Fig. 2. (a) Simplified diagram of the SHIVA process and (b) artist's view of the reactor.

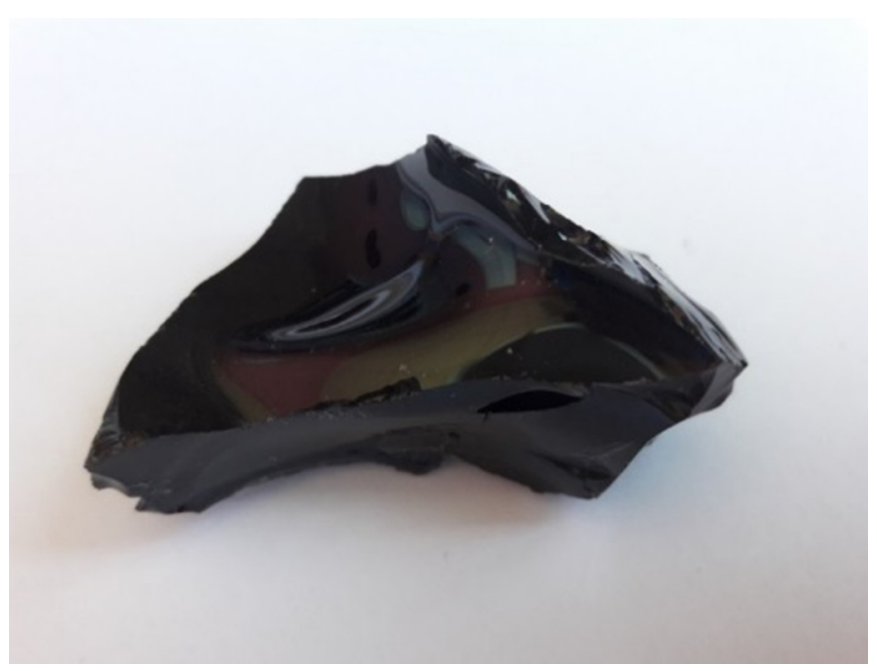

Fig. 3. Waste glass sample from the SHIVA trial.

exchange resin), and strong base IXR. Inputs of SHIVA process are composed of $38.5 \mathrm{wt} . \%$ of waste and $61.5 \mathrm{wt} . \%$ of glass frit.

The end-product of the process is an alumino-borosilicate glass which is macroscopically (millimetre scale: visual inspection) homogeneous (Fig. 3).

Thus, the SHIV A trial conducted in the framework of the THERAMIN project proved the capability of the process for the thermal treatment of a mixture of organic and mineral waste composed of zeolites, diatoms and ion exchange resins. The waste load of $38.5 \%$ is high and can be expected that it could be increased in the future. Indeed, during this feasibility trial, it was not sought to maximise the waste load and the processing capacity. The waste product is an alumino-borosilicate glass, macroscopically homogeneous and its long term behaviour can be characterised according to proven methodologies in order to enable consideration with confidence in its disposability.

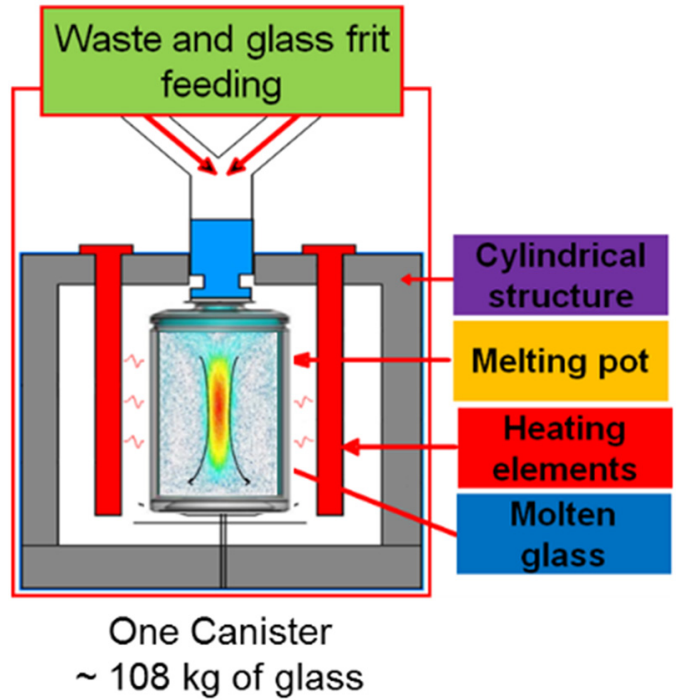

Fig. 4. Simplified diagram of the In-Can Melter process.

\section{In Can (CEA/Orano)}

The In-Can Melter process can support liquid or solid waste feeds. With the current gas treatment process used in THERAMIN trials, it can only tolerate limited amounts of organic matter. Small amount of metal can also be accepted in the waste to be treated. The design ensures that the process can operate remotely for high-activity waste. The design can also be adapted for dealing with plutonium containing material in gloveboxes. The final product of the process can be glass, glass ceramic or simply a high-density waste product.

In-Can Melter is a metallic crucible melter heated in a simple refractory furnace using electrical resistors (Fig. 4). The can is renewed after each filling. 
To prepare the THERAMIN trial, preliminary tests were conducted at the laboratory scale to select the best operating conditions and thus obtain an optimised waste load and a high quality end-product. These tests aim to demonstrate the feasibility of the confinement in a vitreous matrix of by-products coming from existing incineration processes. In the preliminary tests, different amounts of ashes and glass frit are brought into contact $\left(1100^{\circ} \mathrm{C}, 2 \mathrm{~h}\right)$, with or without an adjuvant (e.g. sugar or bentonite). Tests are carried out at a few gram scale. At the end of the tests, the crucibles are cut after immobilisation in epoxy resin and the products obtained are observed under a binocular magnifier. The criteria for the choice of the optimum conditions are the obtaining of a homogeneous glass and the limitation of the expansion during the elaboration.

The preliminary laboratory tests proved the feasibility of ashes vitrification with a high load of $50 \mathrm{wt} . \%$ in the endproduct. Tests also proved the benefits of adding a sugarbased or a bentonite-based adjuvant up to $10 \mathrm{wt} . \%$ to eliminate volatile dust and ensure the best reactivity.

\section{Thermal treatment process based on thermal gasification (VTT)}

Thermal gasification is a process converting solid or liquid organic matter to gaseous products and thus this technology responds very well to the need to reduce the volume of organic radioactive waste. VTT has developed thermal gasification for demanding applications from 1980s and the experience and knowhow has also been applied for treatment of LILW containing organic matter (IXR or operational waste, etc.). The developed process is compact and thus it can be operated at the nuclear power plant site.

Thermal treatment by gasification results in fine dust, which is collected by high temperature filter. In addition to filter dust, larger inorganic particles are removed from the process together with bed material. This mass stream consists primarily of bed material. In most cases filter dust and bottom ash have to be immobilised after waste treatment before final disposal.

The thermal gasification process developed by VTT is based on fluidised-bed (FB) gasification. In FB gasification bed material is fluidised by blowing gasification air or other gasification agent from the bottom of the reactor. Fluidised-bed gasifier can be as a bubbling bed or circulating fluidised-bed type reactor. Both of them can be applied for thermal treatment of LILW and are also used in THERAMIN demonstration test trials.

The test treating a total of $325 \mathrm{~kg}$ of organic IXR was carried out using the pilot scale CFB gasification test facility (Fig. 5). Total duration of the trial was $26.5 \mathrm{~h}$.

The success of test is assessed by determining the conversion of carbon in feedstock to gaseous form i.e. calculating the carbon mass balance for the test. In TERAMIN test the carbon conversion to gas and tars was 92-96 wt.\%, which means that the removal of the organic material from the IXR was good.

The gasification treatment demonstration verified very efficient removal of organic matter from ion exchange resin

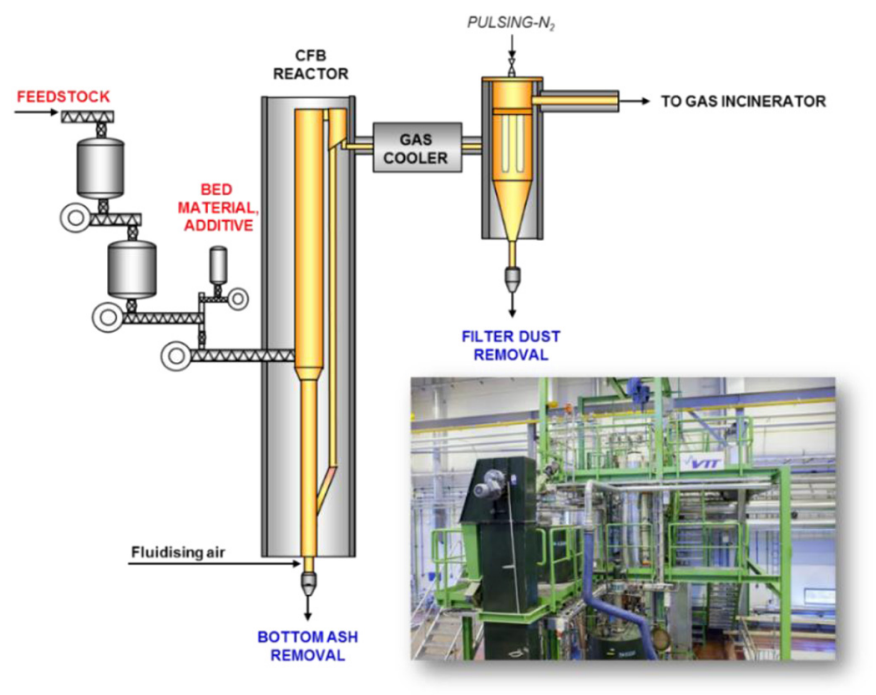

Fig. 5. Pilot-scale Circulating Fluidised-Bed (CFB) gasification test rig.

and very significant volume reduction of the treated waste. The advantages of CFB type gasifier compared to bubbling fluidised-bed (BFB) reactor are related to capacity per cross-sectional area of the reactor, which is much higher in CFB. CFB enables also better heat and mass transfer in the reactor.

\section{GeoMelt (NNL)}

NNL and Veolia Nuclear Solutions in collaboration have established an active GeoMelt In-Container Vitrification (ICV) system at Sellafield. This ICV is used to demonstrate the treatment of a wide range of UK based waste streams. The ICV system installed at the NNL Central Laboratory is presented in Figure 6.

In the THERAMIN framework two waste streams were selected for thermal treatment demonstration tests using the GeoMelt system. The waste streams selected were:

- TH01- A cementitious waste stream representing sea dump drums or failing cement wastes packages;

- TH02- A sludge waste made up of a naturally occurring zeolite (clinoptilolite), sand, Magnox storage pond sludge and miscellaneous contaminants known to arise in a range of UK feed streams.

The GeoMelt ICV system was successfully used for thermal treatment demonstration of $279 \mathrm{~kg}$ of representative cementitious waste (TH-01) with a pre-treatment waste loading of $49 \%$.

Macroscopic observation of the product indicated that the product was a glassy monolith with broad homogeneity. Based on visual inspection it can be expected that the product should be disposable against all key disposability criteria. When the product was sampled it was observed that at least some of the original metallic objects present in the simulated waste remained on completion of processing. All plant operating parameters during this melt were as expected (Fig. 7). 


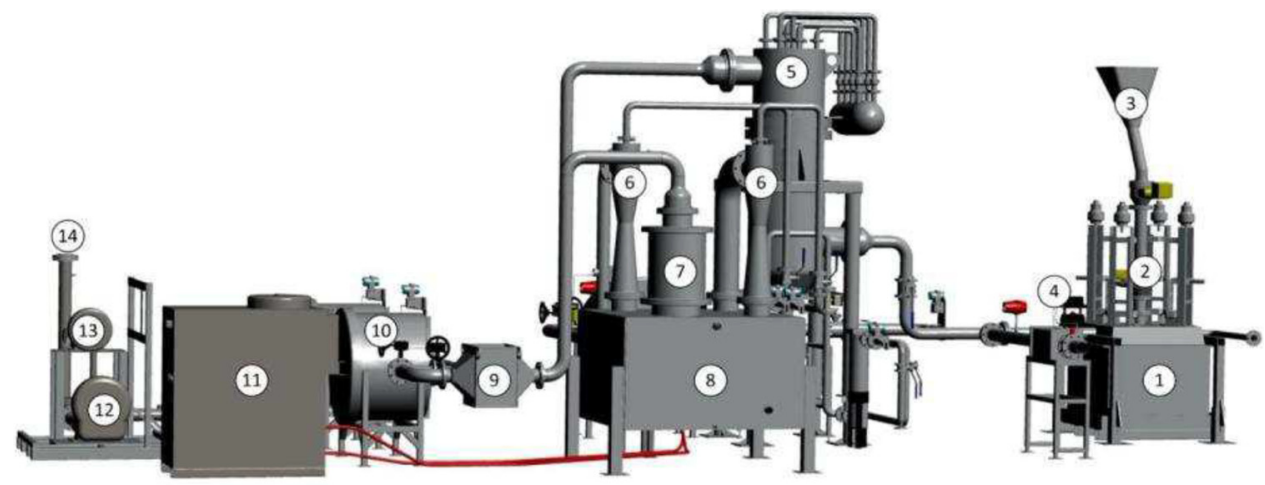

Fig. 6. The GeoMelt system installed at the NNL Central Laboratory. (1. ICV melter, 2. feed chute, 3. feed hopper, 4. connection to off-gas, 5. sintered metal filter, 6. scrubber column, 7. demister, 8. scrubber tank, 9. off-gas heater, 10. HEPA filtration, 11. cooler, 12. off-gas blower, 13. back-up blower and 14. vent discharge).

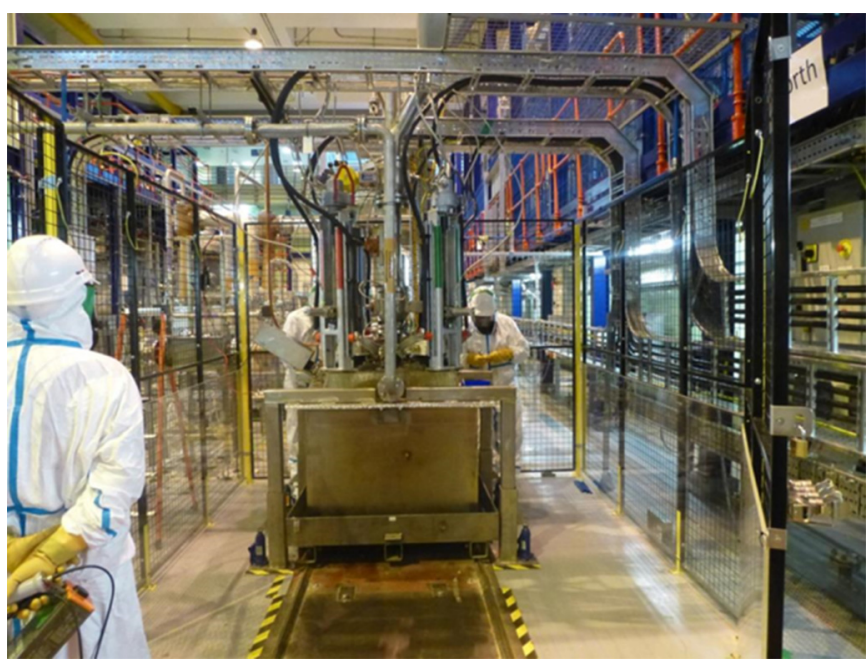

Fig. 7. GeoMelt container.

A sludge stream of $238 \mathrm{~kg}$ (TH-02) was also successfully treated by GeoMelt. Sludge stream consisted of clinoptilolite, sand and Magnox sludge and a pre-treatment loading was $72 \%$. Visual inspection showed that the product of thermal treatment also had a glassy appearance and appeared to be homogenous.

\section{Hot isostatic pressing (NNL and USFD)}

The HIP is a process where pre-prepared waste is sealed in a steel can and the can is exposed to a high pressure at elevated temperature. This treatment results in a monolithic waste form, which is suitable for ongoing storage and ultimate disposal. A schematic is shown in Figure 8. The HIP system consists of a water cooled steel pressure vessel, containing a molybdenum furnace and a thermal barrier shield. The canister is placed inside the furnace before applying high pressure using argon gas while simultaneously increasing temperature.

In the THERAMIN project HIP technology was demonstrated by USFD in $30 \mathrm{~g}$ scale and NNL in 81 scale
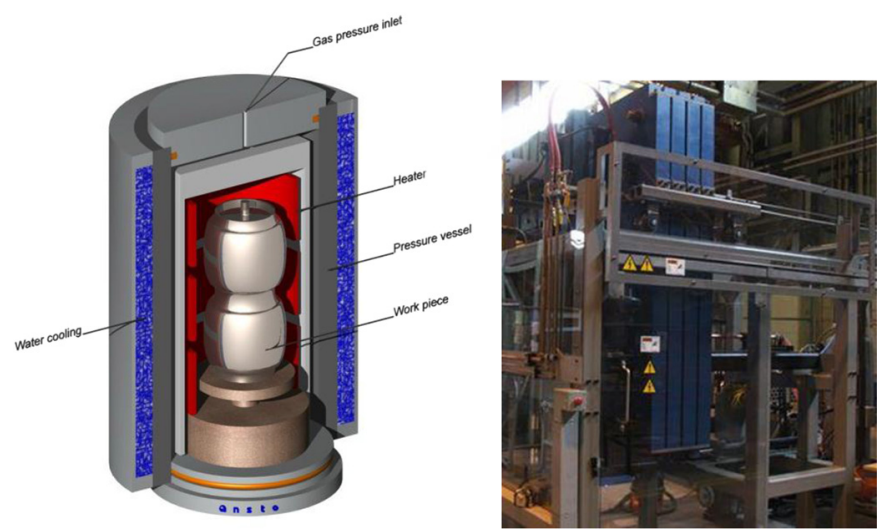

Fig. 8. Schematic of HIP (left: courtesy of ANSTO) and HIP installed at NNL Workington (right).

in order to test the scalability of the process. USFD trailled the immobilisation of magnesium hydroxide sludges, where five waste streams typical of those present of the Sellafield site were investigated. Advantage was taken of USFD's active capability to add triuranium octoxide $\left(\mathrm{U}_{3} \mathrm{O}_{8}\right)$, a major constituent of the Sellafield waste stream. At NNL Workington two HIP runs were carried out on similar sludge feeds using cerium as a surrogate for uranium.

Visual observation of the cans post HIP showed that the cans had consolidated as expected suggesting a successful pressure/temperature cycle had been applied. The cans were then sectioned and the produce observed prior to analysis. Such visual observation of the product suggests that the product of the trials, THERAMIN HIP 1 and HIP 2, could both be suitable for disposal in a UK repository concept.

Seven conceptual waste forms were successfully prepared and HIPed USFD using unique active furnace isolation chamber (AFIC) system that allows processing of radioactive waste simulants in the HIP without risk of contamination to the processing equipment that was utilised when using $\mathrm{U}_{3} \mathrm{O}_{8}$ to simulate a component of the Magnox sludges atypical of those found on the Sellafield Ltd site. Following successful 
calcination, canister packing and bake-out steps, HIP processing of waste forms MBS-U low, NNL-U and NNLCe were carried out. Due to difficulty achieving and maintaining the target pressure of $100 \mathrm{MPa}$ with problems in pressurising the HIP, a reduced target pressure of $75 \mathrm{MPa}$ for the remaining waste forms was used. This is thought to be adequate to consolidate the samples. This was confirmed on completing the sample analysis.

\section{Development of generic disposability criteria}

Samples from each demonstration and samples from thermal treatment processes not tested in the project were characterised in order to evaluate the impacts of thermal treatment on the disposability of radioactive waste. The first step of this evaluation was the identification of the relevant criteria, also called Waste Acceptance Criteria (WAC). Each participating country provided data through a questionnaire. Then, some generic disposability criteria were developed based on examination of these data. The target is that developed generic disposability criteria can be used to evaluate any treated products from any thermal treatment for disposal at any type of disposal facility. These criteria are also independent on the political, regulatory or socioeconomic conditions. They reflect typical characteristics of thermally treated waste products.

\section{Dissemination}

Dissemination and training are also essential activities of the THERAMIN project. For example, all public deliverables can be found and downloaded from the website http://www.theramin-h2020.eu/. In 2020 the project will also organise an international conference focusing on thermal waste treatment technologies.

In addition, a training placement program is a way to promote thermal treatment technologies. Two training placements have been implemented during 2018 and 2019.

This project has received funding from the Euratom research and training programme 2014-2018 under grant agreement No 755480 .

Cite this article as: Matti Nieminen, Markus Olin, Jaana Laatikainen-Luntama, Stephen M. Wickham, Slimane Doudou, Adam J. Fuller, Jenny Kent, Maxime Fournier, Sean Clarke, Charlie Scales, Neil C. Hyatt, Sam A. Walling, Laura J. Gardner, Stephane Catherin, Benjamin Frasca, Thermal treatment for radioactive waste minimisation, EPJ Nuclear Sci. Technol. 6, 25 (2020) 